AIAA-2001-1263

\title{
STRUCTURAL DYNAMICS EXPERIMENTAL ACTIVITIES IN ULTRA-LIGHTWEIGHT AND INFLATABLE SPACE STRUCTURES
}

\author{
Richard S. Pappa \\ Structural Dynamics Branch \\ NASA Langley Research Center \\ Hampton, VA 23681
}

\author{
John O. Lassiter \\ Structural and Dynamics Test Group \\ NASA Marshall Space Flight Center \\ Huntsville, AL 35812
}

\author{
Brian P. Ross \\ Structural Dynamics Test Engineering \\ NASA Goddard Space Flight Center \\ Greenbelt, MD 20771
}

\begin{abstract}
This paper reports recently completed structural dynamics experimental activities with new ultralightweight and inflatable space structures (a.k.a., "Gossamer" spacecraft) at NASA Langley Research Center, NASA Marshall Space Flight Center, and NASA Goddard Space Flight Center. Nine aspects of this work are covered, as follows: 1) inflated, rigidized tubes, 2) active control experiments, 3) photogrammetry, 4) laser vibrometry, 5) modal tests of inflatable structures, 6) in-vacuum modal tests, 7) tensioned membranes, 8) deployment tests, and 9) flight experiment support. Structural dynamics will play a major role in the design and eventual in-space deployment and performance of Gossamer spacecraft, and experimental R\&D work such as this is required now to validate new analytical prediction methods. The activities discussed in the paper are pathfinder accomplishments, conducted on unique components and prototypes of future spacecraft systems.
\end{abstract}

\section{INTRODUCTION}

NASA is focusing renewed attention on the topic of large, ultra-lightweight space structures, also known as "Gossamer" spacecraft." 2 New materials and new structural concepts including inflatables offer the possibility of creating space structures that are orders of magnitude larger and/or lighter than existing ones. ${ }^{3}$ This technology can enable many new classes of missions within the next 5-30 years, such as:

- Space observatories with collectors of $30 \mathrm{~m}$ or larger in size with sub-millimeter surface accuracy

This paper is declared a work of the U.S. Government and is not subject to copyright protection in the United States.
- Solar sails of $100 \mathrm{~m}$ or larger in size with areal densities of less than $2 \mathrm{~g} / \mathrm{m}^{2}$

- Orbital transfer vehicles with large inflatable concentrators for solar thermal propulsion

- Next-generation space telescopes with large membrane sunshields for passive cooling

- Space solar power collectors and transmitters that are hundreds or even thousands of meters in size

- Inflatable habitats for the International Space Station or future lunar or planetary exploration

A predominant design factor for future ultralightweight space structures is their dynamic response to applied loads, which is correspondingly larger than for heavier structures. Therefore, structural dynamics will play a major role in the development and eventual in-space deployment and performance of these systems. Structural dynamic analytical prediction methods for Gossamer spacecraft are mostly unproven., ${ }^{4}$ Ground and flight tests of prototype hardware are required as soon as possible to validate the accuracy and sufficiency of these new analytical methods.

Initial experimental work along these lines has been accomplished recently at the Langley Research Center (LaRC), the Marshall Space Flight Center (MSFC), and the Goddard Space Flight Center (GSFC), and this paper summarizes these activities. Due to the uniqueness of the structures being tested, experiments conducted to date generally have required as much effort in developing the test methods themselves as in acquiring the specific test results. Test procedures used for traditional aerospace structures are mostly not applicable. Therefore, the results presented in this paper are pathfinder accomplishments, to be undoubtedly followed by improved experimental methods and facilities in the months and years ahead. 
This paper discusses nine recent examples of structural dynamics experimental activities with Gossamer-related structures. Three topics come from each contributing Center, as follows:

\section{Langley Research Center (LaRC) \\ 1. Inflated, Rigidized Tubes \\ 2. Active Control Experiments \\ 3. Photogrammetry}

\section{Marshall Space Flight Center (MSFC) \\ 4. Laser Vibrometry \\ 5. Modal Tests of Inflatable Structures \\ 6. In-Vacuum Modal Tests}

\section{Goddard Space Flight Center (GSFC)}

7. Tensioned Membranes

8. Deployment Tests

9. Flight Experiment Support

There is considerable synergism and overlap between these nine topics, and related efforts in several areas are underway at more than one Center.

\section{STRUCTURAL DYNAMICS EXPERIMENTAL ACTIVITIES}

\section{Inflated, Rigidized Tubes (LaRC)}

The Langley Research Center, in cooperation with the Jet Propulsion Laboratory (JPL) and the Department of Defense (DoD), is developing a database of measured structural characteristics of inflated, rigidized tubes suitable for space application. These tubes can serve as primary load-bearing members for many Gossamer concepts, such as large space solar power satellites. ${ }^{6} \mathrm{LaRC}$ will perform static load tests on each tube to measure its axial stiffness, bending stiffness, and buckling resistance. ${ }^{7}$ Most test articles for the program have a length-to-diameter ratio (L/D) of approximately 10 , with diameters of approximately 4 , 5 , or 6 inches. Two long tubes with an L/D of 100 (6in. diameter) are also available for testing for comparison with short tubes of similar construction.

To supplement the static test results, vibration tests will also be conducted on some of the tubes. Figure la) shows a set of eight 4-in.-diameter inflated, rigidized, composite tubes that were tested in a cantilevered configuration as shown. Figures $I(b)-(d)$ show the approach used for axial, bending, and torsional vibration tests with tip impact excitation and two miniature accelerometers. The main objective of the tests is to calculate the effective Young's Modulus $(E)$ and Shear Modulus (G) of each tube from the experimental natural frequencies. To validate the testing and data analysis procedures, several aluminum "calibration specimens" (with known E and G) were also tested. Figure 1(a) also shows one of the calibration specimens. In each test, data were acquired with varying amounts of added tip mass ranging from 10 to 500 grams. Figure 1(b) shows an example of an added mass. Acquiring data sets with varying tip mass increased the confidence in the calculated structural properties.

This test program will measure structural parameters for many leading types of inflated, rigidized tubes. It will examine the effects of rigidization technique, manufacturing procedure, and the method of packaging for launch, all of which can significantly affect structural performance. The resulting database will provide validated structural parameters for Gossamer spacecraft designers. In the future, the program will expand to include inflatable, rigidizable trusses, which will be tested in a similar manner.

\section{Active Control Experiments (LaRC)}

Figure 2 shows a proof-of-concept active vibration control experiment conducted at LaRC. The objective was to demonstrate that the damping of the first bending mode of the structure could be increased to at least $5 \%$ of critical damping using embedded piezoactuators. The test article is the lower, darkcolored tube seen in Figure 2(a). It is a 3-ft-long, 4inch-diameter, inflated, rigidized composite tube with embedded actuators. Prior to inflation and curing, it was flattened and then $\mathrm{z}$-folded, like an accordion, as tubes of this type can be folded for launch into space. A 3- $\mathrm{ft}$ piece of white plastic pipe is attached to the top of the composite tube as a dummy mass, lowering the bending frequency to the desired value of $10 \mathrm{~Hz}$ to simulate the fundamental vibration frequency of a proposed mission.

Four 2.25 in. $\times 3.375$ in. piezoelectric patch actuators are embedded in the wall of the composite tube near its base at 90-degree intervals around the circumference. These piezoactuators were developed 
in-house and are called Macro Fiber Composite (MFC) actuators. ${ }^{n}$ They use the $d_{33}$ mode of the piezoelectric material to achieve an operational efficiency that is about twice as high as more commonly used $\mathrm{d}_{31}$-mode piezoelectric devices ( 500 microstrain $/ \mathrm{kV} / \mathrm{mm}$ vs. 250 microstrain $/ \mathrm{kV} / \mathrm{mm}$ ). Additional features of the MFC actuator are its high maximum free strain level $(-2000$ microstrain peak-to-peak), directional strain capability, and high flexibility and durability.

For active vibration control, the experiment used a basic analog feedback circuit with gain adjustment. The feedback signal is the fore-aft vibration velocity of the tube measured with a laser vibrometer. Only the front and rear piezoactuators are used, and they are wired out-of-phase electrically to work together in bending. Figure 2(b) shows the open-loop versus closed-loop free-decay vibration response of the tip of the beam. Without control (open loop), the natural damping of the first bending mode is $0.4 \%$, corresponding to a freedecay vibration period greater than 10 seconds. With control (closed loop), the damping increases to $8 \%$, a factor of 20 increase, corresponding to a free-decay vibration period of only 1 second. Future experiments of this type will use digital controllers, which will enable even higher damping levels to be obtained.

Follow-on work is underway to also examine the effectiveness of piezoactuators for static shape adjustment of Gossamer structures. In particular, it may be possible using these devices to remove unwanted shape distortions of a structure before it is rigidized in space. Work is also underway on better defining actuator performance in a simulated space environment. Although piezoelectric patch actuators have performed with good success in several previous aeronautics applications, e.g., to twist helicopter blades or reduce buffet loads in aircraft tails, ${ }^{9}$ the harsh space environment poses new design and implementation challenges for their use.

\section{Photogrammetry (LaRC)}

Photogrammetry is the science of calculating the three-dimensional coordinates of physical objects using photographs. ${ }^{10}$ It is a leading candidate technology for measuring the static shape and/or motion of future ultra-lightweight and inflatable space structures. It offers the simplicity of taking photographs coupled with good to excellent measurement precision. With time series of images (typically from video cameras), it is usually referred to as "videogrammetry" or "videometrics" and is used in many diverse engineering applications, such as to measure the deformation of aircraft wings in wind tunnels. ${ }^{11}$

Research is underway at LaRC to begin addressing the technical challenges and requirements of photogrammetry and videogrammetry for Gossamer structures. Techniques will be developed to measure structures in both air and vacuum environments in one or more of the following three conditions, listed according to the anticipated level of difficulty:

- Stationary (least difficult)

- Vibrating

- Deploying

Figure 3(a) shows one of the test articles recently used in this research. It is a $5 \mathrm{~m}$-diameter inflatable parabolic reflector attached with thin cords at its perimeter to an inflatable Kapton torus. The total weight of the structure is approximately $4 \mathrm{~kg}(8.8 \mathrm{lbs})$. SRS Technologies of Huntsville, AL manufactured this structure for NASA in 1996 under a research and technology development contract. In space, this concept can serve as either a radio-frequency antenna or as a solar concentrator for electrical power generation and/or propulsion. The photograph shows the rear, convex surface of the reflector, which is covered with more than 500 retro-reflective targets for photogrammetry. The other side of the antenna (not visible) has three struts arranged in a tripod configuration for holding the antenna feed. In this work, the struts attach to a stiff support frame.

The static shape of the reflector was measured in the initial investigation. There were two main research objectives: 1) Determine the photogrammetric measurement precision obtained using multiple consumer-grade digital cameras and 2) Gain experience with new commercial photogrammetry software packages, specifically PhotoModeler Pro from Eos Systems, Inc. Photographs were taken from four different positions using four separate Kodak DC290 (2. I-megapixel) digital cameras. Using four different cameras simulated the future objective of measuring vibrating or deploying Gossamer structures with multiple, time-synchronized cameras. To minimize air currents, the tests were conducted (at room temperature 
and pressure conditions) inside a $16 \mathrm{~m}$-diameter vacuum chamber at LaRC. Details of this project are documented elsewhere. ${ }^{12}$

Figure 3(b) shows the final results of the photogrammetric calculations. The software calculated this dense wireframe model using the photogrammetrically obtained $3 \mathrm{D}$ points. Using a leastsquares analysis, the best parabolic surface representing the complete set of 521 measurement points was calculated. The focal length of this parabolic surface was 120.09 inches, which compared closely with the design focal length of 120 inches. The root-meansquare deviation over the entire $5 \mathrm{~m}$-diameter reflector surface from an ideal parabolic shape was approximately 1.5 millimeters.

Figure 3(c) shows the corresponding measurement precisions of the calculated $3 \mathrm{D}$ points (at 95\% probability). This important information is a by-product of the photogrammetric calculations with the Bundle adjustment method. The overall measurement precision is summarized by the mean values for each direction. ( $\mathrm{X}$ is horizontal, $\mathrm{Y}$ is vertical, and $\mathrm{Z}$ is longitudinal.) The cameras photographed a $6.5 \mathrm{~m}$ test article (including the torus); therefore these average precision values correspond to 1:28000 (1 part in 28000) in the $X$ direction, 1:14000 in the $Y$ direction, and 1:5000 in the $\mathrm{Z}$ direction. These are moderate photogrammetric precision levels, but would be acceptable for many uses of the data. Additional tests conducted on the $5 \mathrm{~m}$ antenna have shown that these precision values can be improved, as expected, by increasing the number of camera locations and/or the resolution of the cameras. Future experiments at LaRC will build upon these experiences gained in measuring the static shape of the $5 \mathrm{~m}$ inflatable antenna and will progress to also measuring vibrating and/or deploying structures.

\section{Laser Vibrometry (MSFC)}

A laser vibrometer is a sophisticated instrument that measures the surface vibration velocity in the direction of the laser beam only at any point on a structure that the laser illuminates. Laser vibrometry is a mature, though costly, measurement technology. ${ }^{13}$ The vibrometer used at MSFC is an Ometron scanning vibrometer system, which can scan from point to point on the structure by moving internal mirrors under computer control. The obvious and primary benefit that a vibrometer provides is noncontacting response measurement. This approach avoids the undesirable mass-loading effects of a traditional array of accelerometers. Even the added mass and stiffness of accelerometer cables can appreciably affect the dynamic response of an inflatable structure. This section discusses various experimental methods developed and used at MSFC over more than three years of testing ultra-lightweight and inflatable space structures with a laser vibrometer system.

Figure 4(a) shows one laser position used in a recent modal test of a $5 \mathrm{~m}$ inflatable antenna/solar concentrator at MSFC. ${ }^{14}$ This structure is the same one discussed in the previous section of the paper. (It was moved to LaRC following this modal test.) Note that the vibrometer can operate at long distances from the test article. Additional measurements were also made with the vibrometer at other locations relative to the structure. Figure 4(b) shows how the structure was excited with an electrodynamic shaker attached to one of the three struts. Because the inflatable portion of the structure is so lightweight (about $9 \mathrm{lbs}$ ), a dynamic force level of less than $\mathrm{I} \mathrm{lb}$ is sufficient to excite vibrations that are easily measured with the vibrometer. Figure 4(c) shows one of the mode shapes identified in the test.

The Ometron vibrometer system can be operated remotely via a serial computer interface. This capability was required in the modal test of an inflatable structure located inside a vacuum chamber. The vibrometer cannot operate in vacuum and had to be outside the chamber. At this facility, only one porthole was available to view the structure from outside. This porthole was in a very inaccessible location. The solution was to place only the vibrometer and a minimum amount of test hardware near the porthole and to control the vibrometer with a personal computer located about 20 feet away via the serial interface. All inflatable structure dynamic tests have used this computer interface, including those that had no restrictions on where the vibrometer could be located.

All of the inflatable structures tested at MSFC have been primarily constructed of thin-film materials that are transparent. A laser vibrometer must detect some reflected laser light from the structure in order to make the measurement, which will not occur if it is too transparent. This can also occur if the surface is too 
reflective, in which case all non-perpendicular laser beams deflect entirely away from their source. To circumvent this problem, retro-reflective targets have been used in every modal test. A small section of adhesive retro-reflective tape (usually $0.5 \mathrm{sq}$. in. or less) is attached at each response point. Such small pieces of tape, which are only a few mils thick, have little effect on the structural dynamic response characteristics. They have been used for tests with up to 60 response points. Small pieces of retro-reflective tape have also often been placed perpendicular to the surface to permit measurements to be made in directions parallel to the surface of the structure. These perpendicular pieces of tape serve as "corner cubes." Of course, consideration must always be given to potential damage of an ultra-lightweight or inflatable structure when removing any type of surface preparation, especially for thin membranes.

For testing small subcomponents of inflatables or ultra-thin membranes, the application of any reflective tape as a surface preparation could unacceptably alter the structural response. Other methods may need to be investigated to obtain adequate laser return signals. For example, to test a $\mathrm{I}-\mathrm{m}^{2}$ ultra-thin membrane, reflective tape could be avoided completely if the test article were constructed of an opaque material (a diffuse white surface is best). Selecting a specific type of membrane material to simplify making the vibration measurements may be feasible in certain research tests. A diffuse sprayed-on paint coating could also possibly be used. In this case, only a small area near each response point would be sprayed by carefully masking the surrounding area.

Another practical factor to consider is measurement errors that occur when the laser beam is not aligned with a coordinate axis of the structure. Recall that the vibrometer measures only the component of velocity in the direction of the laser beam. Positioning the vibrometer to be parallel with an axis for every response point is impractical for large structures with numerous points. These off-axis errors have been addressed using two different methods. The first method approximates the vibration component in the desired axis by dividing the measured vibrometer response data by the appropriate direction cosine. This is a good approximation if the angle between the laser beam and the coordinate axis is relatively small or if the motion at the measurement point is predominately in the direction of the coordinate axis. The other method is to position the laser vibrometer a long distance from the structure and aligned in the axis direction. The difficulty here is that the test requires a vacant facility substantially larger than the test article. Also, at long distances it can be difficult to see the measurement targets at some locations. Another practical problem that occurs in many tests it that it is difficult to locate the vibrometer along one or more of the coordinate axis. For example, in the $5 \mathrm{~m}$ antenna modal test shown in Figure 4, it was impractical to locate the vibrometer high above the structure to measure the vertical component of vibration.

To allow three-dimensional velocity measurements to be obtained more easily and accurately with the vibrometer, MSFC recently purchased the LMS International CADA-X Laser Vibrometer Interface (LVI). This package integrates with an existing CADA$X$ suite of software that MSFC uses for large modal tests. The LVI controls the scanning of the laser and coupled with the Fourier Monitor module of CADA-X, it calculates frequency response functions (FRFs). To obtain FRFs along each axis using the LVI, vibrometer measurements must be acquired for the same set of response points using three or more non-coplanar vibrometer locations. The LVI uses these datasets and least-squares analysis to calculate FRFs corresponding to each coordinate axis. Of course, if the measurements do not contain sufficient information in one of the axis directions, then the resulting data for that axis may be noisy.

\section{Modal Tests of Inflatable Structures (MSFC)}

MSFC has conducted modal tests of five full-scale inflatable structures ranging in size from approximately 6 to $21 \mathrm{ft}$, as shown in Figure 5. All of the structures were torus-supported concentrators with application to solar thermal propulsion systems or radio transmitter/receiver systems (antennas). These modal tests have been fully documented in test reports and several have been described in technical papers and in a recently published book on Gossamer spacecraft. ${ }^{15-17}$ This section discusses some of the experiences and lessons learned in conducting the modal tests of these unique inflatable structures.

Both free-free and fixed-base boundary conditions have been used. In free-free tests, low-stiffness springs 
suspended the smaller inflatable concentrators for modal testing. These springs had the lowest practical stiffness to minimize the suspension natural frequencies. However, there was still considerable coupling between the suspension system and the lowfrequency test article dynamics. For future free-free tests, MSFC is considering a commercially available active/passive suspension system that has been used successfully elsewhere for modal tests of a variety of heavier space structures. Those tests achieved vertical suspension frequencies on the order of $0.2 \mathrm{~Hz}$, which closely approximates the unconstrained boundary conditions of Earth orbit. When suspending much lighter inflatable structures, however, the same system may not be able to achieve such good low-frequency performance due to the practical difficulty of removing all residual friction in the device.

The last two modal tests used fixed-base boundary conditions. Both structures were supported by three composite struts, and the ends of the struts opposite the torus and lenticular connected to a circular interface plate using several bolts, nuts, and brackets. In the first test (TSC-6 $2 \times 3$ structure), the interface plate was bolted to the floor with the struts cantilevered from it. However, the identified mode shapes showed that cantilevered conditions were not achieved. The excessive response was attributed to free play in the connection hardware. With lightweight structures, joints are more lightly loaded than with heavier structures so that free play can be more of a problem. In the second test ( $5 \mathrm{~m}$ structure), the three struts connected to a fiberglass support stand. There was no pre-test analytical model of the combined test article and stand, so it was unknown if the test article dynamics would couple with the stand. Therefore, the stand and struts were instrumented with accelerometers. The identified mode shapes showed that the fixture was stiff enough to provide fixed-base boundary conditions for the first five modes. When good pre-test analytical predictions are not available, it is best if possible to include the support fixture as part of the structure under test.

Space inflatables will use membrane materials that are only a few mils or even a few microns in thickness. Their internal pressures will generally be as low as possible to minimize membrane stresses. These two conditions cause extremely low local stiffness, or in other words, extremely high local flexibility. Therefore, applying a dynamic excitation force directly to an inflated component will typically produce insufficient forces for modal testing due to the high local flexibility. In all of the tests conducted at MSFC, an electrodynamic shaker was attached to a noninflated component such as a metal interface plate or a composite strut. Even in these cases, however, much smaller force levels than typically encountered in modal tests occur. Therefore, high-sensitivity load cells are used with inflatable structures. These sensors are 50 times more sensitive than those used in most other modal tests. Higher sensitivity allows better resolution of smaller forces, which in turn allows better calculation of the FRFs.

It is difficult not to affect the dynamics of a lightweight inflatable structure to some degree when using attached shakers. In the modal test of the $5 \mathrm{~m}$ antenna, for example, selection of the shaker location along the length of the strut was found to significantly affect the resulting mode shapes of the structure. With the shaker at approximately the center of the strut, the modes were far from being symmetric, whereas by moving the shaker closer to the end of the strut where it is stiffer, the modes became more symmetric and reasonable. Both MSFC and LaRC are investigating alternative methods of exciting inflatable structures for modal tests, in particular, using piezoelectric actuators bonded to the surface of the test article.

The extremely low weight and stiffness of inflatable structures make them particularly sensitive to extraneous disturbance forces, which can corrupt the dynamic response measurements. To date, all inflatable structures tested at MSFC have required a continuous re-supply of gas to maintain a constant pressure due to leaks around seams or small holes. The flow of gas itself into and out of an inflatable is a source of unmeasured, extraneous dynamic excitation. In the test of the $5 \mathrm{~m}$ structure, the pressurization system could not be turned off long enough to acquire a complete set of FRFs without the structure deflating excessively. Therefore, it was not possible to obtain data sets with both the air supply turned on and then off to assess the effects of this dynamic disturbance source. Other disturbance sources that must be minimized when testing inflatable structures include nearby vibration and acoustic sources, as well as the ambient airflow in the laboratory from the air conditioning system. 
The subject of nonlinear dynamic response is another important factor for inflatable structures. Considerable information exists on the analytical aspects of the nonlinear structural response of inflatables. However, there is not yet much corroborating experimental data available. In early tests at MSFC, sinusoidal sweeps were performed to identify those force levels that produced linear response of the structure and the force levels of greater magnitudes that produced nonlinear response. A significant result of these tests is the identification of the bifurcation process, which is the splitting of one mode into two at increasing force levels. ${ }^{18}$ Another result of these tests is the conclusion that the response of an inflatable due to any force level can be described as being chaotically modulated.

\section{In-Vacuum Modal Tests (MSFC)}

It is well known that thin-film membranes vibrating in air will have lower natural vibration frequencies and higher damping values than when in vacuum conditions. ${ }^{19}$ It is therefore preferable, when possible, to conduct modal vibration tests of these structures in vacuum chambers to more closely approximate the conditions of space. Of course, Gossamer structures larger than approximately $15 \mathrm{~m}$ in size cannot be tested in vacuum because this is the size limit of existing facilities. Tests in vacuum conditions of larger structures can only occur using scale-model test articles.

As mentioned previously, a laser vibrometer cannot operate in vacuum so it must remain outside the chamber. It is entirely possible, however, to obtain good vibrometer measurements with the laser beam passing through a glass porthole of the chamber. If the chamber has multiple accessible portholes, the vibrometer can be moved from location to location, and the resulting data sets can be transformed into threedimensional structural response measurements at each test point using the LMS LVI system discussed earlier.

Moving the vibrometer to multiple viewing ports may not be possible with certain vacuum chambers. For example, in the modal test of the Pathfinder 3 structure conducted in vacuum in the large X-Ray Calibration Facility (XRCF) at MSFC, only one porthole was available. Figures 5(c) and 6 show this inflatable structure inside the chamber and the test configuration, respectively. To acquire vibrometer data in more than one axis, the test article needed to be rotated. The test objectives also required data acquisition at three different air pressure settings. Ideally, vibration data should be measured in both orientations of the structure holding the ambient pressure constant to ensure that the measured vibration data in each axis corresponded to exactly the same operating conditions of the chamber. However, to rotate the structure required that the chamber be depressurized, opened, then repressurized, which took more than 12 hours to perform. To substantially reduce the overall testing time at some risk of data inconsistency, the decision was made to conduct the vibration tests in the first structural orientation at all three air pressures and then to repeat it for the second structural orientation. Additional details of this modal test of the Pathfinder 3 structure in the $\mathrm{XRCF}$ vacuum chamber are available elsewhere. ${ }^{15}$

There are several other potential problems associated with conducting modal vibration tests in vacuum chambers. For example, shaker overheating could occur due to the lack of airflow that allows heat dissipation. Difficulties in supporting a shaker either by a fixture or a suspension device may also occur due to lack of space in small chambers. The application of piezoactuators for excitation of inflatable structures in dynamic tests will possibly eliminate this problem. At vacuum conditions, extraneous acoustic excitation will not occur due to the lack of air. However, some form of isolation may be required with ultra-lightweight structures to eliminate any unwanted excitation from structure-borne vibration that could come from vacuum pumps or other chamber machinery. Cleanliness and outgassing concerns are also often important when conducting tests in these facilities.

\section{Tensioned Membranes (GSFC)}

During the past two years, the Goddard Space Flight Center conducted two modal tests on a onetenth-scale model of the Next Generation Space Telescope (NGST) sunshield to support structural analytical model validation. Because the sunshield surface is thin membrane material, the tests were conducted in vacuum conditions to avoid the effects of air on the membranes. This was the first time that GSFC has conducted tests of this type. Many lessons were learned during these two modal tests that are applicable to future testing of membrane structures. 
Figure 7(a) shows the main components of the test article. They are: a central aluminum mounting block, four aluminum support tubes with their corresponding tip hardware, and four membranes. The overall dimensions of the structure are $1.5 \mathrm{~m} \times 3.5 \mathrm{~m}$. Each of the four membrane layers is 13 -micron-thick (0.5-milthick) Kapton film whose outer side has a reflective gold coating and whose inner side has a vapordeposited-aluminum coating. The model dimensions were selected using constant-thickness scaling laws. This approach keeps the membrane thickness the same between full and sub-scale models. The membranes attach to the support tubes only at the comers using constant-force springs that apply a preload of $1.425 \mathrm{~N}$ $(0.32 \mathrm{lb})$ to the membranes. The test article was oriented vertically in both modal tests to minimize gravity effects on the membranes. Tests were conducted with the long side of the membrane down and then with the short side down to compare the effects of gravity on the membrane response. An Ometron scanning laser vibrometer measured the outof-plane vibration of the outer membrane.

The first modal test occurred in March 1999 in GSFC Chamber 238 , a $3.7 \mathrm{~m} \times 4.6 \mathrm{~m}$ vertical vacuum chamber. The sunshield was attached to a large steel block that hung from the top of the chamber by thin threaded rod. An electrodynamic shaker located outside the chamber provided the dynamic excitation with the connecting rod to the structure (stinger) feeding through a mechanical bellows in the chamber wall. The laser vibrometer system was also outside the chamber with the sensor head positioned at a porthole to have a view of the sunshield. A drawback of this set-up was that the excitation direction and the laser vibrometer line-of-sight could not be aligned. Also, the stinger connected to the steel block at an angle, which resulted in undesirable fixture modes being excited.

The second modal test occurred in July 2000 in the GFSC Space Environment Simulator, a $8.2 \mathrm{~m} \times 12.2 \mathrm{~m}$ vertical vacuum chamber. This test built upon the lessons learned in the first test. The shaker was moved into the chamber so that the test article excitation could be better controlled. Also, a new rigid support fixture was designed whose modes of vibration were all higher in frequency than all of the sunshield modes of interest. Sunshield modes of interest were in the range of $1-10$ $\mathrm{Hz}$. The resulting set-up was a tower-like fixture with an electrodynamic shaker mounted on top, as shown in Figure 7(b). The sunshield attached directly to the shaker armature with a triaxial force transducer sandwiched between them. The fixture, the sunshield central block, and the tube tips were instrumented with triaxial accelerometers. Figure $7(\mathrm{c})$ shows the test article and support fixture in the vacuum chamber. This larger chamber allowed the laser vibrometer, which was again located outside the chamber and viewing through a porthole, to have a field of view that encompassed the entire sunshield, which did not occur in the first modal test. To help minimize total testing costs, considerable preliminary testing was done in air outside the chamber to become familiar with the test set-up and to allow the time in the chamber to be more productive.

A large amount of data was collected during almost two weeks in the chamber during this second test. The identified modes have reasonable agreement with the analytical predictions. ${ }^{20}$ Figure $7(d)$ is a velocity contour plot of the $1.8 \mathrm{~Hz}$ mode from the laser vibrometer system. This is the lowest-frequency membrane mode of the short-side-down configuration. Due to schedule restrictions, the time in the chamber was spent primarily collecting data with minimal time spent reviewing the data. After the test, a problem was discovered in the data from one of the test configurations. Because of this, additional testing is planned to recollect data for this configuration. Future testing will also investigate the effect of membrane tension by collecting data with different strength constant-force springs at the tube tips.

Other issues needing review prior to additional testing are the test fixture configuration and the force transducer selection. Since the sunshield mounted directly to the shaker armature, the force transducer had to support a static shear load due to the weight of the structure. Therefore, the selected force transducer was not as sensitive as it should be for measuring the small dynamic forces used to excite the lightweight membranes. Alternate set-ups will be investigated to allow the use of more-sensitive force transducers.

\section{Deployment Tests (GSFC)}

The one-time, in-space deployment process for a Gossamer spacecraft will always be a mission-critical step of the program. Therefore, understanding the deployment structural dynamics will typically be as 
important, or even more important, than understanding the post-deployment dynamic characteristics. In support of the development of the Next Generation Space Telescope (NGST) sunshield, which will be a large, lightweight, multiple-membrane structure that deploys from a folded-up launch configuration, GSFC sponsored the design, manufacture, and ground deployment test of a one-half-scale model of the "strawman" concept. This section discusses the test article and the deployment test, which was performed at ILC Dover, Inc. Other participants in the program were GSFC, JPL, and L'Garde, Inc. The ground test article had the following specifications:

- One-half-scale model of NGST strawman design

- 4 membranes, two on each side of the supports

- $2.5-\mathrm{cm}$ separation between membranes at support platform, increasing to $15.0 \mathrm{~cm}$ at the free edge

- Lowest natural frequency greater than $0.2 \mathrm{~Hz}$.

- Boom material shall be aluminum laminate, and membrane material shall be 0.5 -mil Kapton $\mathrm{HN}$

- Boom safety factor of 4 in Euler buckling

- 8-degree cant angle in the membrane ends

- Membrane wrinkling is not an issue as long as the membranes do not touch

The goals of the deployment test were to evaluate the various characteristics of the deployment, such as the unfolding behavior of the membranes, the straightness and stiffness of the deployed booms, the impulse forces that would be imparted to the spacecraft, and the post-deployment system planarity. Also important was the need to verify that the packaging and deployment procedures would eliminate trapped gas and the threat of puncture during deployment.

Figure 8 shows the ground test article in both a partially deployed and then a fully deployed state. Details of the packaging and deployment sequence of the structure are as follows. The membranes were $\mathrm{z}$ folded in the lateral direction first followed by the longitudinal direction, secured with membrane retainer clips, then placed into membrane enclosures on the central container. The central container was mounted on a rigid support stand. The inflatable tubes were then attached to the container and membranes. Weight-relief lines were attached to both longitudinal tubes and the upper lateral tube. The lateral tubes were then pressurized and deployed simultaneously, after which weight-relief lines were also added to the membranes.
The longitudinal tubes were then pressurized and deployed simultaneously. Lastly, the tubes were depressurized. Over the course of the program, four deployments were performed.

A major lesson learned from the deployments was that the gravity effects were greater than anticipated. Longitudinal tube deflection required a vertical suspension line at the center span of the tube, and suspension lines were also added to prevent buckling in the longitudinal tubes at the low inflation pressures. The membranes tended to fall out of the folded stack during the deployment and resulted in switching from dispensing clips to a retainer dispensing design. There was also a problem with static electricity attraction between the membrane layers that was eliminated by adding a static-charge dissipative coating to the membranes. $^{21}$

\section{Flight Experiment Support (GSFC)}

Figure 9 shows the Inflatable Sunshield in Space (ISIS) flight experiment, which GSFC and JPL have been developing during the past several years. Unfortunately, the ISIS experiment was cancelled recently, and all work has stopped. Nevertheless, the research and development that occurred in planning and designing this flight experiment is excellent information concerning the issues that need to be addressed in any future flight experiment with large Gossamer structures. This section summarizes the ISIS experiment and its structural-dynamics-related aspects.

The ISIS test article is a 1/3-scale model of the GSFC strawman concept for the NGST sunshield. The objectives of the experiment are to gather data characterizing the dynamic behavior of a large thin-film membrane structure for analytical model correlation and to demonstrate controlled deployment and rigidization of a large inflatable sunshield in space. The experiment would provide important data on the dynamic response of such a structure without the influence of gravity. It would also be the first test in space of a large inflatable structure using controlled deployment.

The experiment structure consists of two subsystems, the support structure and the thermal shield. The support structure is a Hitchhiker cross-bay bridge to which is mounted a telescoping mast that 
supports a container and four inflatable booms arranged in a cross configuration. The thermal shield is four layers of 13-micron-thick (0.5-mil-thick) Kapton membranes with vapor-deposited-aluminum (VDA) coating. The membranes connect to the container and to the ends of the inflatable booms. Constant-force springs attach the membranes to the booms and keep the sunshield under constant tension. The inflatable, rigidizable composite booms are constructed of the following layers, starting with the innermost layer: a Kapton bladder for inflation, a graphite epoxy layer that supplies the structural stiffness once heat-cured in space, a Kapton outer restraint layer, and a multi-layerinsulation (MLI) sleeve. In the stowed configuration, each boom is flattened and rolled up onto a cylinder attached to the tip hardware. Immediately prior to deployment, the booms are heated to approximately 20 $\operatorname{deg} \mathrm{C}$ to soften them. During deployment, the booms inflate with nitrogen gas at $3.2 \mathrm{psi}$, which causes the booms to unroll from the cylinders. After deployment, the booms are heated which causes the graphite epoxy layer to cure and harden. After curing, the booms are allowed to cool down to ambient temperature. Once cooled, the nitrogen gas is vented. ${ }^{23}$

Desired instrumentation for the experiment includes triaxial accelerometers, force transducers, thermistors, pressure transducers, and cameras. An encoder system will condition and digitize the transducer signals. The digitized data will be recorded on a laptop computer in the crew cabin. Triaxial accelerometers will be mounted at the ends of the booms, inside the container, and at the base of the telescoping mast. Force transducers positioned between the container and mast will measure the input force to the sunshield. Video from the Shuttle cameras will be recorded and photogrammetry techniques will be applied after the flight to obtain position information of the boom during deployment and of the outer layer of membranes during dynamic characterization tests. The Space Shuttle reaction control system (RCS) jets will provide the primary excitation for the experiment. In addition, some data will also be acquired during quiet times when all excitation is off.

The instrumentation selection process is more difficult for this flight experiment than for typical laboratory tests. There are additional restrictions on size, weight, and location for accelerometer placement because all instrumentation must be installed prior to deployment. All accelerometers must fit in the limited volume of the boom tip since the remainder of the boom is rolled up prior to deployment. This also means that accelerometer cables must be as few in number and as flexible as possible to allow proper boom deployment.

The accelerometers must also be as lightweight as possible to not significantly mass-load the boom. However, it is difficult to have a small accelerometer that is sensitive enough to measure the anticipated level of $10 \mu \mathrm{g}$ for the Shuttle background noise level. Additionally, all instrumentation must survive launch loads and operate in the space environment.

Selection of the excitation source was also a difficult process. Various excitation systems and methods were investigated. It was believed that designing and implementing a dedicated excitation system for the experiment was too prohibitive in cost and schedule. Analytical simulations based on preliminary impulse profile information showed that target modes would be sufficiently excited with RCS jet firings ${ }^{24}$ Final simulations using more accurate impulse information have not yet been performed. Although the preliminary simulations showed RCS jet excitation is acceptable, it is not an ideal situation and does have some issues that need to be addressed. The jet impulses are not as controllable as a typical shaker set-up. The impulse duration must be in increments of 80 milliseconds, and it is not yet clear if a pure translational input in the desired direction is possible. Also, the impulses from RCS jet firings are all at a fixed amplitude, making it more difficult to assess the linearity of the structural response.

\section{CONCLUSIONS}

Future ultra-lightweight and inflatable spacecraft, which will be folded and packaged for launch, will experience their maximum dynamic responses during deployment and operation in space. To date, there are no standardized ground test methods for validating the in-space structural dynamic behavior of these structures. Many factors combine to make such tests unusually difficult, including facility size limitations, gravity and air effects, low natural frequencies, nonlinearities, and nontraditional structural measurement approaches, which typically must be noncontacting, optical methods. This paper discussed 
initial work conducted recently at three NASA Centers towards developing and conducting such ground test activities. Many tests of increasingly complex Gossamer-type structures will occur in the future and will build upon these lessons learned to date.

\section{ACKNOWLEDGEMENTS}

Several people at each Center assisted in the experimental work discussed in this paper. We extend thanks for significant contributions by Vaughn Behun, Keats Wilkie, and Louis Giersch at LaRC, Robert Engberg and Jennie McGee at MSFC, and Sebastien Lienard, John Johnston, and Jim Smith at GSFC.

\section{REFERENCES}

1. "The Gossamer Spacecraft Initiative: Technology to See the Unseen Universe," First Gossamer Workshop, Oxnard, CA, October 1999.

2. Chmielewski, A. B., Moore, C. L., and Howard, R., "The Gossamer Initiative," IEEE paper 0-78035846-5/00, January 2000.

3. Belvin, W. K. and Hickey, G. S., "Gossamer Systems: Technology and Concepts," Technology Briefing Presented to NASA Headquarters Code S, August 2000.

4. Clem, A. L., Smith, S. W., and Main, J. A., "A Pressurized Deployment Model for Inflatable Space Structures," AIAA Paper 2000-1808, 1st Gossamer Spacecraft Forum, Atlanta, GA, April 2000.

5. Adler, A. L., Hedgepeth, J. M., and Mikulas, M. M., Jr., "Static and Dynamic Analysis of Partially Wrinkled Membrane Structures," AIAA Paper 2000-1810, 1st Gossamer Spacecraft Forum, Atlanta, GA, April 2000.

6. Derbès, B., "Case Studies in Inflatable Rigidizable Structural Concepts for Space Power," AIAA Paper 1999-1089, 37th Aerospace Sciences Meeting, Reno, NV, January 1999.

7. Watson, J. J., "Static-Test Results for the Characterization of Inflatable Rigidizable Columns," AIAA Paper 2001-1269, 2nd Gossamer
Spacecraft Forum, Seattle, WA, April 2001

8. Wilkie, W. K. et al., "Low-Cost Piezocomposite Actuator for Structural Control Applications," 7th SPIE International Symposium on Smart Structures and Materials, Newport Beach, CA, March 2000.

9. McGowan, A. R. et al., "Aeroservoelastic and Structural Dynamics Research on Smart Structures Conducted at NASA Langley Research Center," Sth SPIE International Symposium on Smart Structures and Materials, San Diego, CA, March 1998.

10. Karara, H. M., Handbook of Non-Topographic Photogrammetry, 2nd edition, American Society of Photogrammetry, Falls Church, VA, 1989.

11. Burner, A. W., Radeztsky, R. H., and Liu, T., "Videometric Applications in Wind Tunnels," 5th SPIE Videometrics Conference, San Diego, CA, July 1997.

12. Pappa, R. S., Giersch, L. R., and Quagliaroli, J. M., "Photogrammetry of a $5 \mathrm{~m}$ Inflatable Space Antenna With Consumer Digital Cameras," NASA TM-2000-210627, December 2000.

13. Tomasini, E. P., editor, Proceedings of the 4th International Conference on Vibration Measurements by Laser Techniques: Advances and Applications, Ancona, Italy, June 2000.

14. Lassiter, J. O. and Engberg, R. C., "5 Meter Inflatable Concentrator Modal Survey Test Report," NASA MSFC Report SOTV-DEV-00069 , October 2000.

15. Engberg, R. C. and Lassiter, J. O., "Dynamic Testing of Inflatable Spacecraft Structures," Sound and Vibration, June 1999, pp. 16-20.

16. Engberg, R. C., Lassiter, J. O., and McGee, J. K., "Modal Survey Test of the SOTV $2 \times 3$ Meter OffAxis Inflatable Concentrator," AIAA Paper 20001639, 41st SDM Conference, Atlanta, GA, April 2000.

17. Lassiter, J. O., et al., "Multidisciplinary Testing of Thin-Film Inflatable Structures," Chapter 11 in Gossamer Spacecraft: Membrane/Inflatable 
Structures Technology for Space Applications, AIAA Progress in Astronautics and Aeronautics, April 2001.

18. Slade, K., Virgin, L., and Tinker, M., "Mode Splitting in an Inflated Polyimide Cylinder with Circumferential Asymmetry," AIAA Paper 20011411, 2nd Gossamer Spacecraft Forum, Seattle, WA, April 2001.

19. Sewall, J. L., Miserentino, R., and Pappa, R. S., "Vibration Studies of a Lightweight Three-Sided Membrane Suitable for Space Application," NASA Technical Paper 2095, January 1983.

20. Lienard, S., et al., "Dynamic Testing of a Subscale Sunshield for the Next Generation Space Telescope (NGST)," AIAA Paper 2001-1268, 2nd Gossamer Spacecraft Forum, Seattle, WA, April 2001.

21. "NGST 1/2-Scale Inflatable Sunshield Deployment," Final Report by ILC Dover. and L'Garde, June 1998.

22. Pacini, L. and Lou, M. C. "Next Generation Space Telescope (NGST) Pathfinder Experiment: Inflatable Sunshield In Space (ISIS)," SAE Paper 1999-01-5517, October 1999.

23. Adams, M. L. et. al., "Design and Flight Testing of an Inflatable Sunshield for the Next Generation Space Telescope (NGST)," AIAA-2000-1797, 1st Gossamer Spacecraft Forum, Atlanta, GA, April 2000.

24. Lienard, S. and Johnston, J. D., "Evaluation of Excitation Systems for the ISIS Flight Experiment," NASA GSFC Memo, November 1999. 

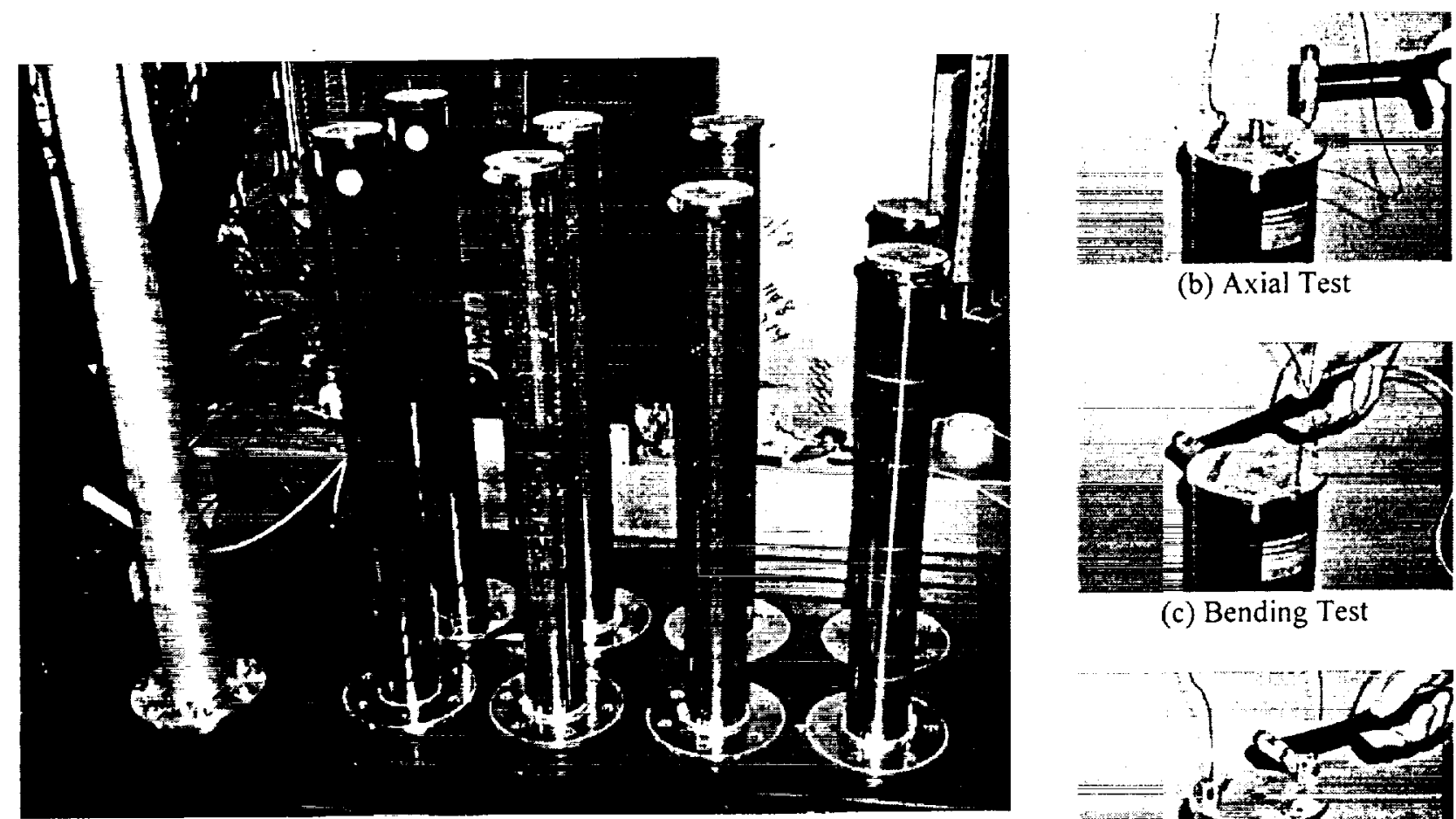

(b) Axial Test

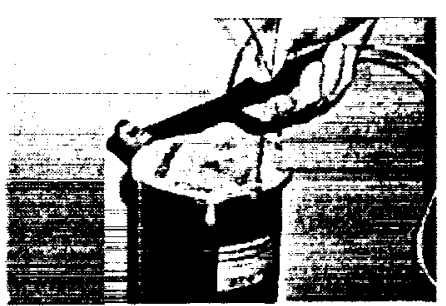

(c) Bending Test

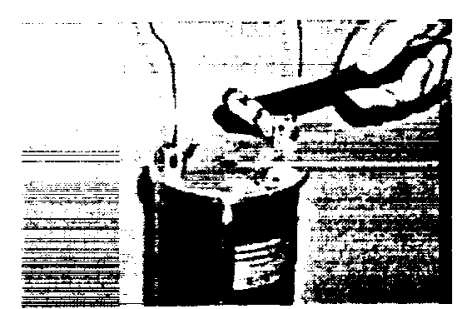

(d) Torsional Test

Figure 1 - Vibration Tests of Cantilevered Inflated, Rigidized Tubes at LaRC.

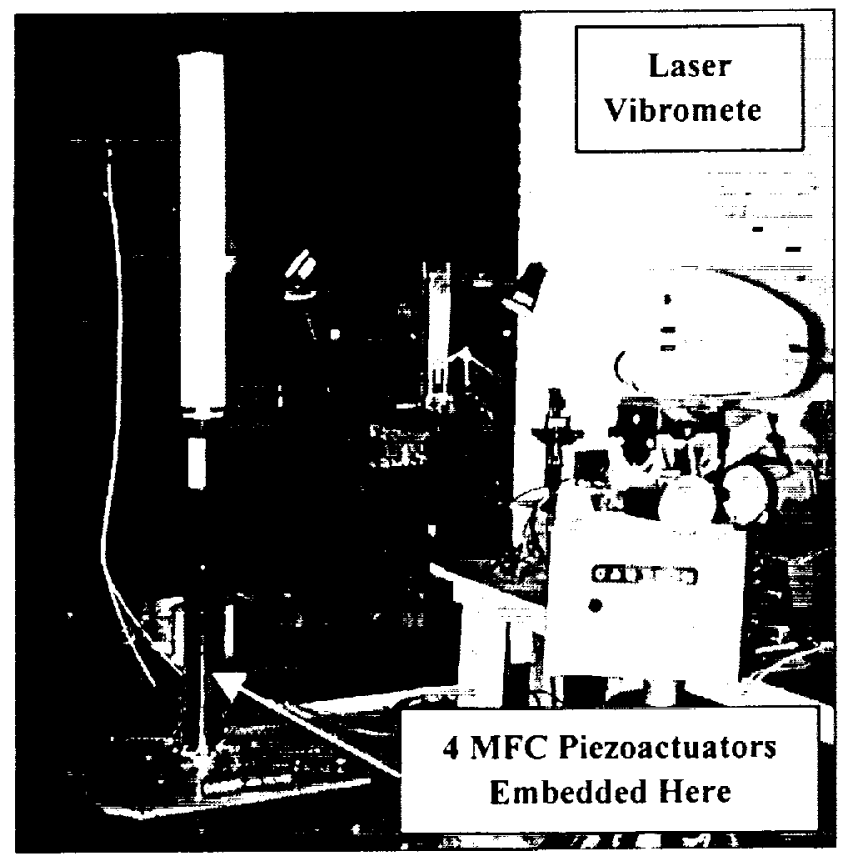

(a) Test Configuration
Excitation

Removed

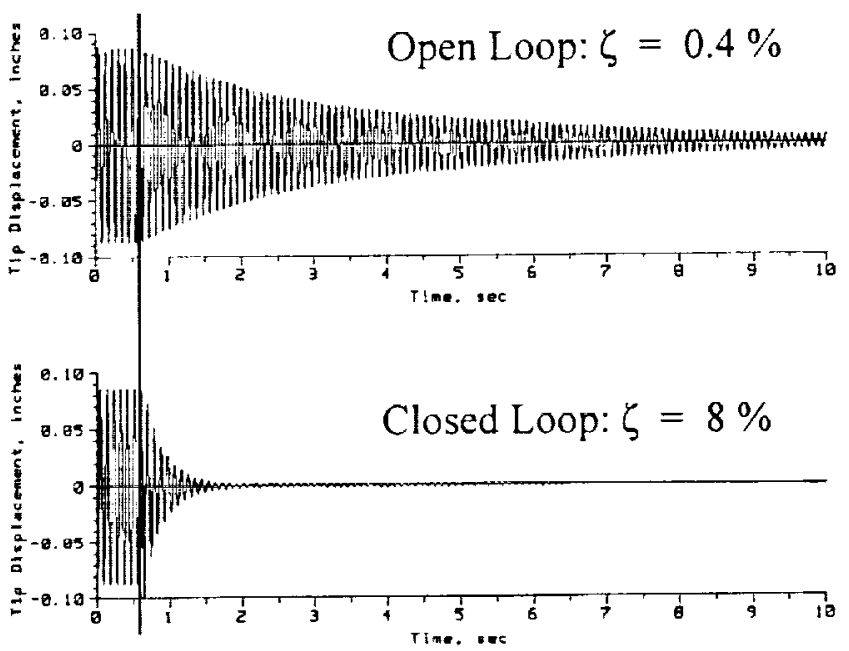

(b) Open-Loop Versus Closed-Loop Free Decay Response

Figure 2 - Active Vibration Control Experiment at LaRC. 


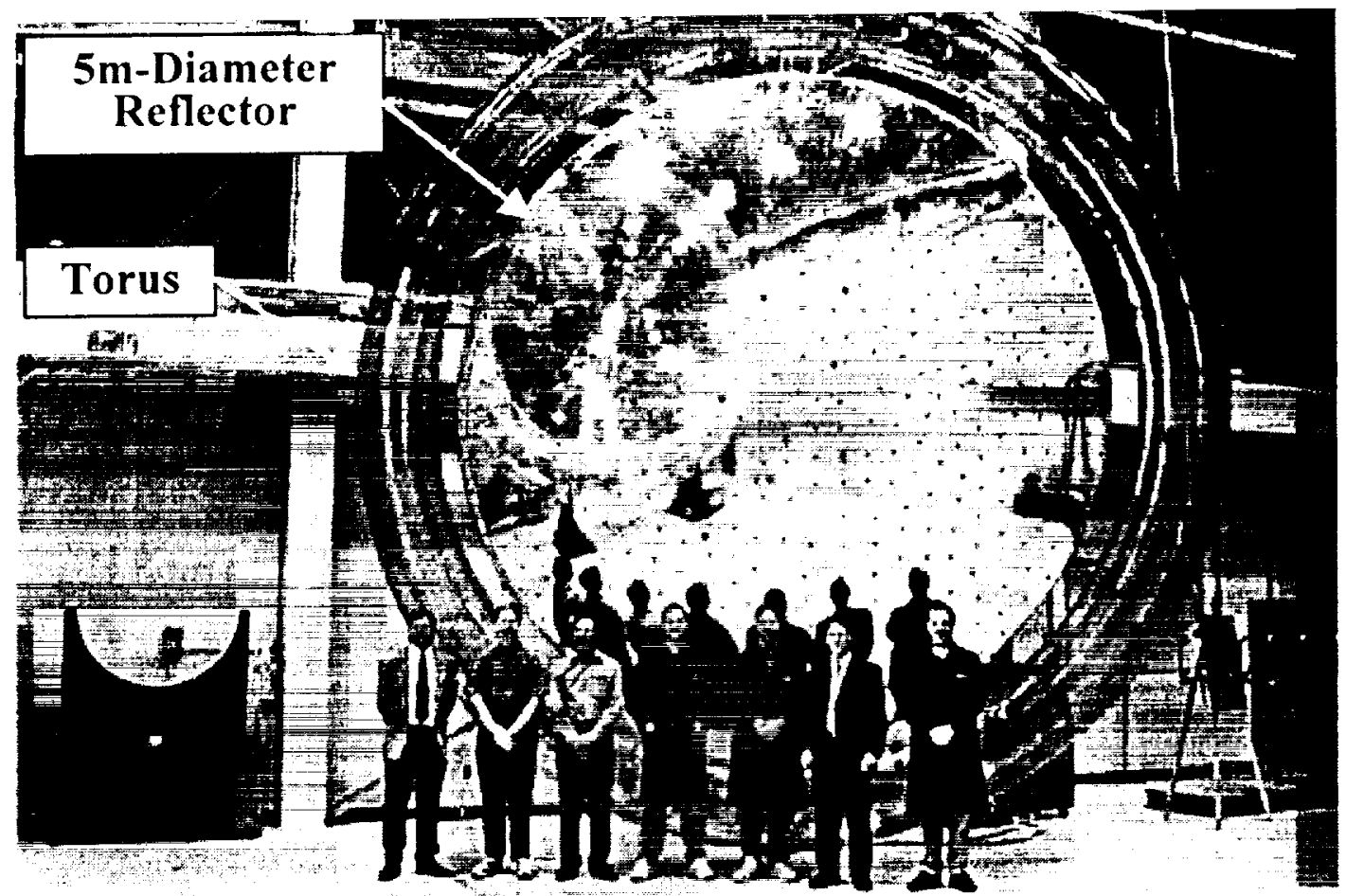

(a) Test Article
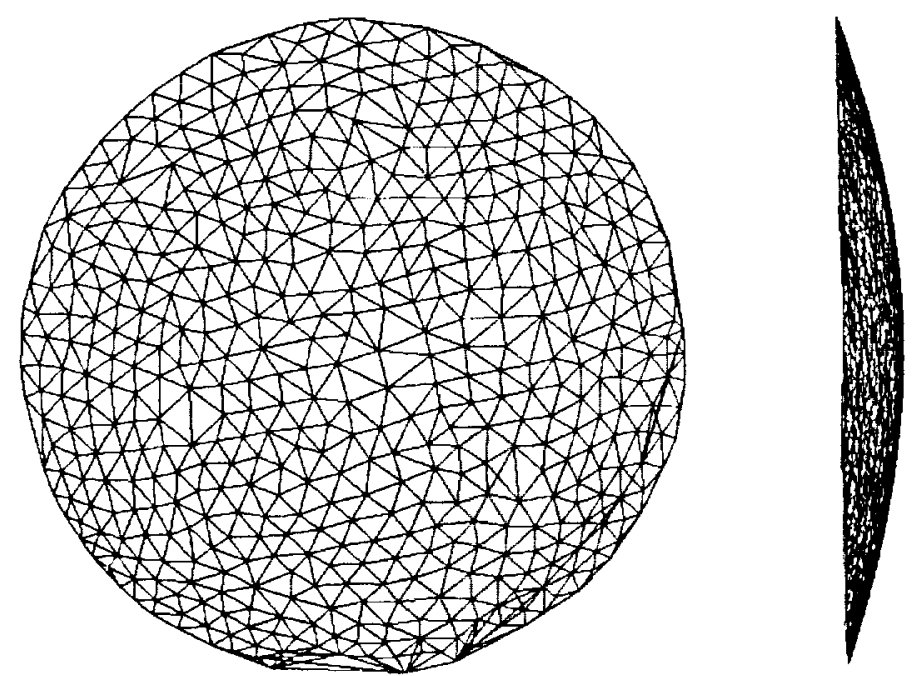

(b) Front \& Side Views of Photogrammetrically Determined 3D Model of Reflector Surface

\begin{tabular}{|c|c|c|c|c|}
\hline Direction & Minimum & Maximum & Mean & Std. Dev. \\
\hline X (horizontal) & 0.003 & 0.023 & 0.009 & 0.004 \\
\hline Y (vertical) & 0.015 & 0.041 & 0.018 & 0.004 \\
\hline Z (out of plane) & 0.037 & 0.112 & 0.052 & 0.024 \\
\hline Root-sum-square: & 0.040 & 0.121 & 0.056 & 0.025 \\
\hline
\end{tabular}

(c) Measurement Precision in Inches for 521 Targets on the Reflector Surface

Figure 3 - Photogrammetric Measurement of $5 \mathrm{~m}$ Inflatable Antenna/Solar Concentrator at LaRC. 


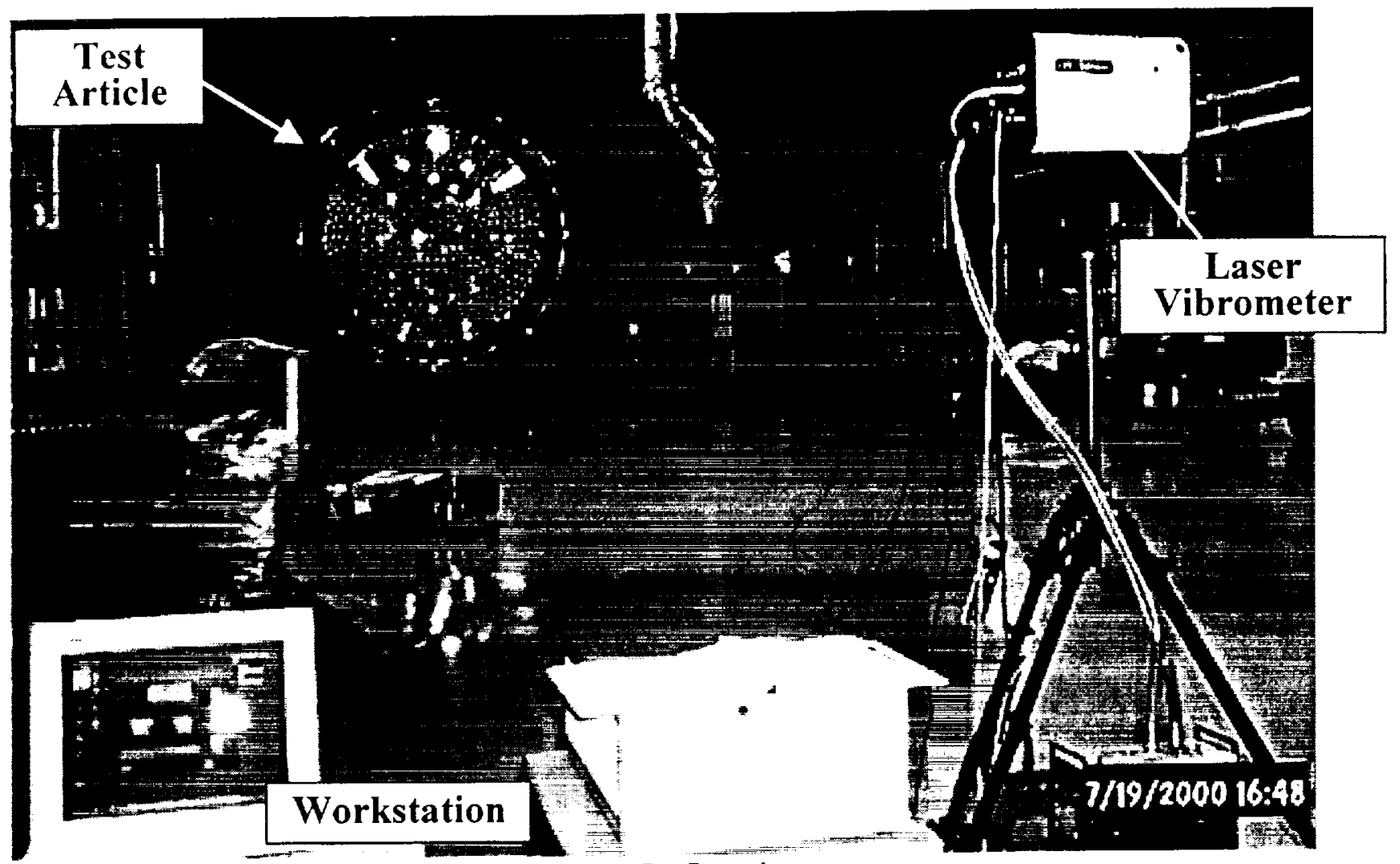

(a) Test Configuration

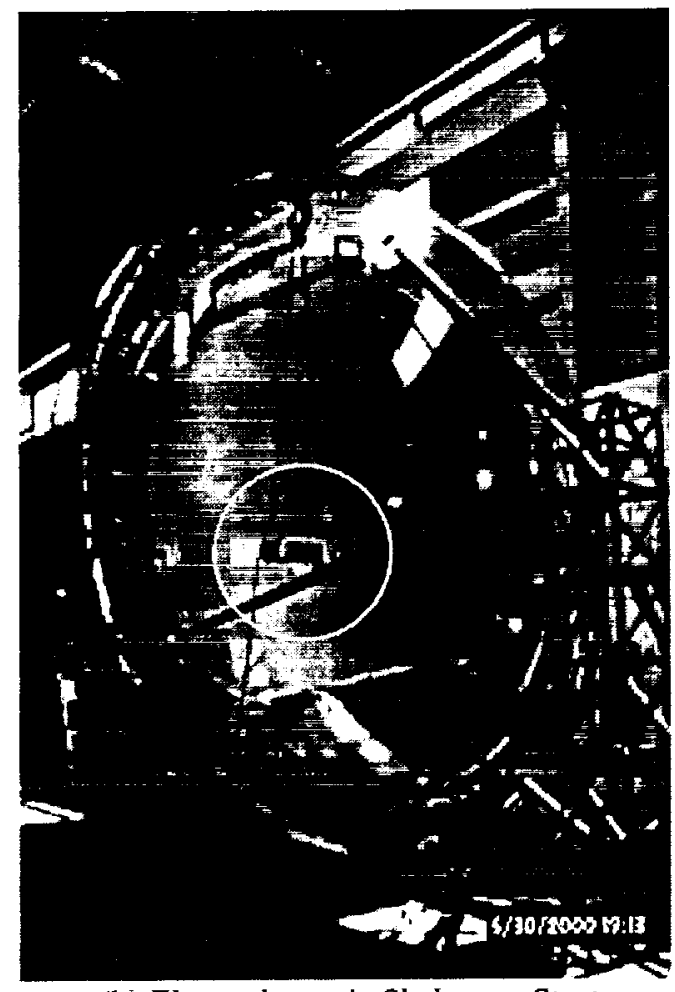

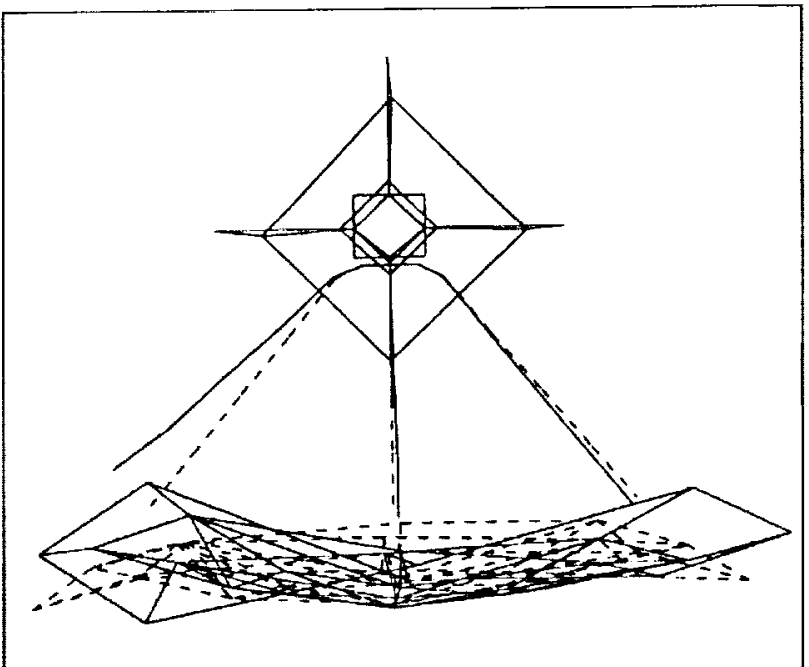

(c) Identified Bending Mode at $4.17 \mathrm{~Hz}$

(Top View)

(b) Electrodynamic Shaker on Strut

Figure 4 - Modal Test of $5 \mathrm{~m}$ Inflatable Antenna/Solar Concentrator Using a Scanning Laser Vibrometer at MSFC. 


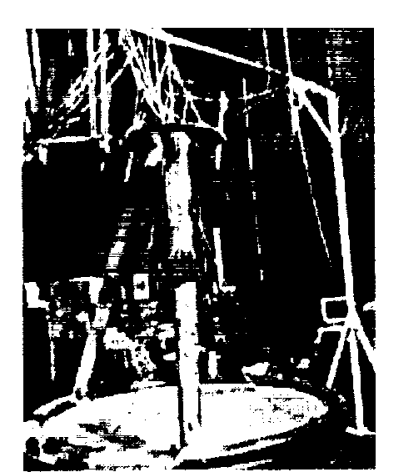

(a) Pathfinder 1 - June 1997

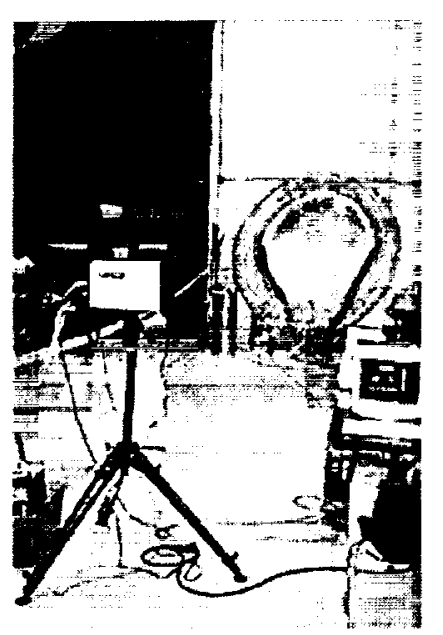

(d) TSC-6 $2 \times 3$ meter- August 1999

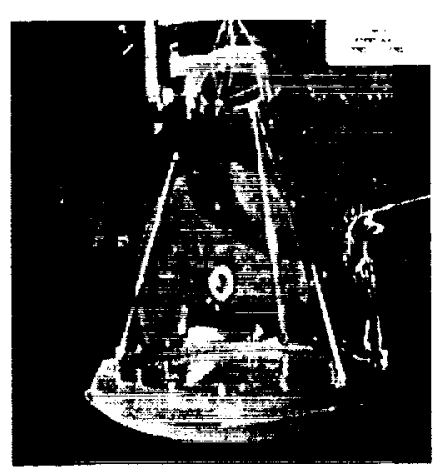

(b) Pathfinder 2 - Oct. 1997

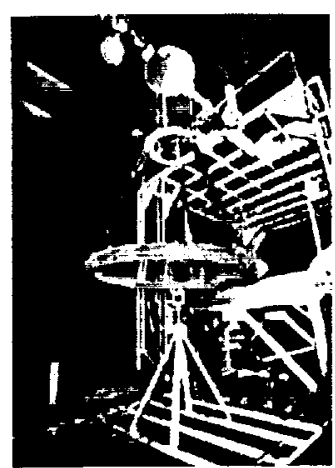

(c) Pathfinder 3 - Oct. 1998

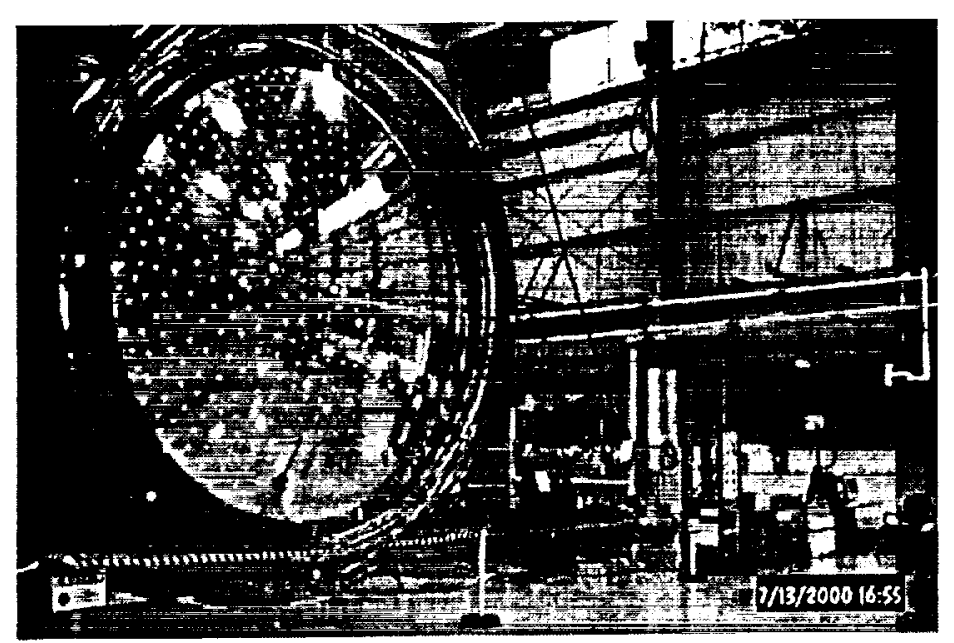

(e) 5 meter - July 2000

Figure 5 - Five Inflatable Solar Concentrators Have Been Tested at MSFC.

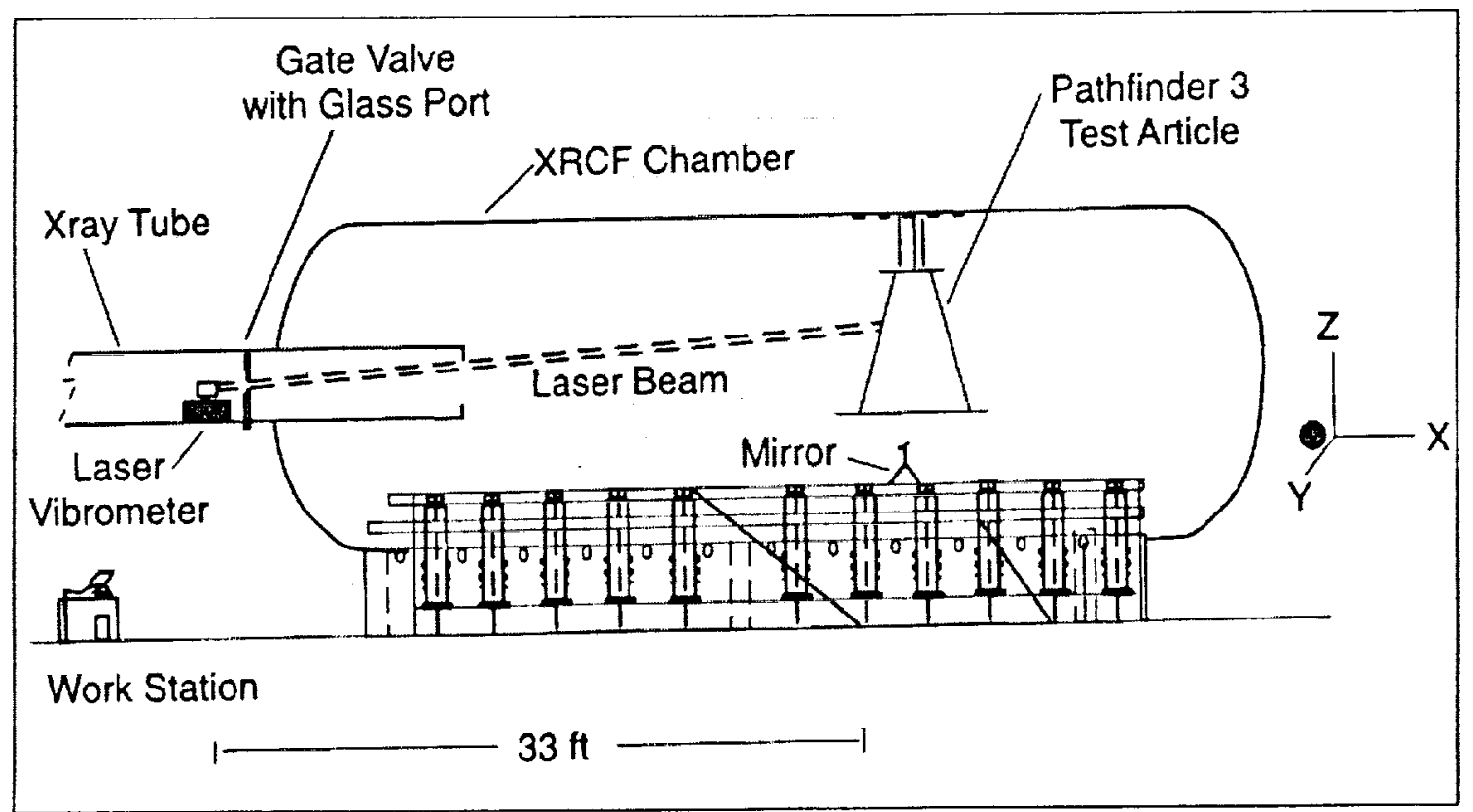

Figure 6 - Pathfinder 3 Modal Test Configuration in Vacuum Chamber at MSFC. 

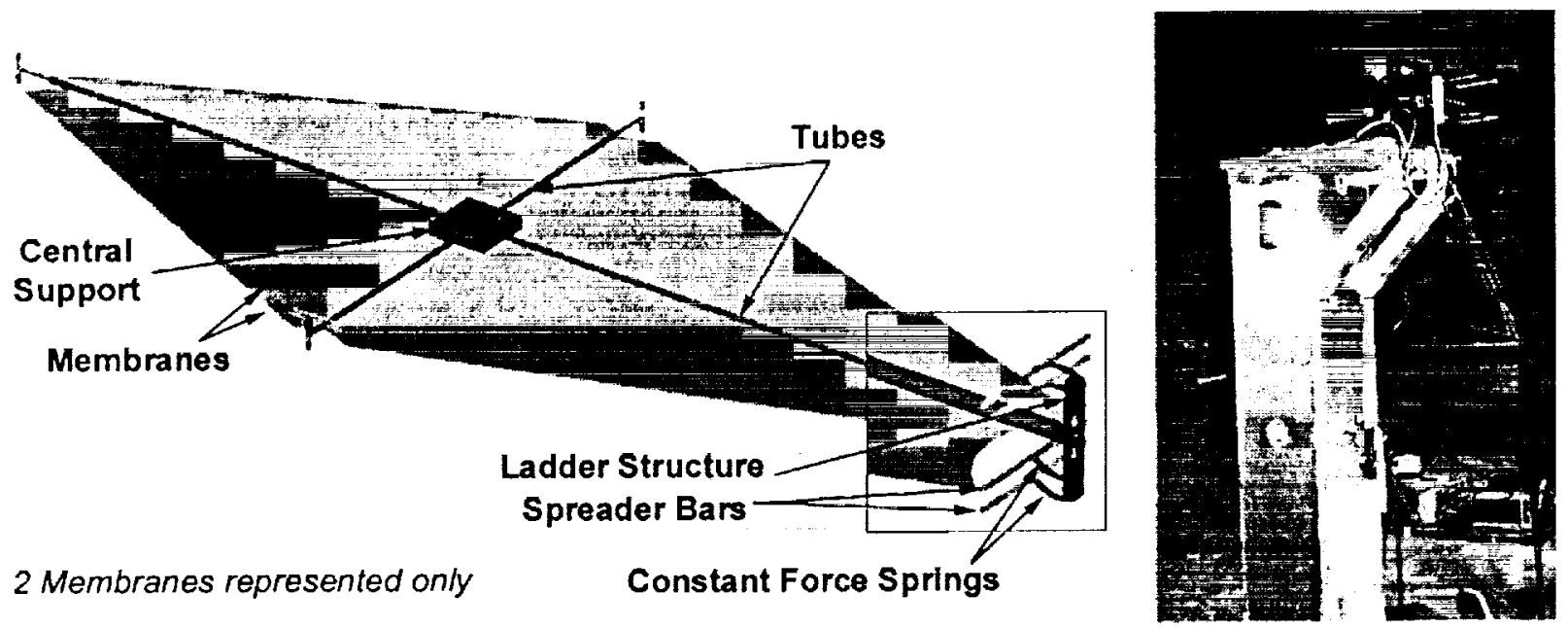

(a) Test Article Components

(b) Shaker Location at Top of Support Fixture (Attaches to Central Support Block)

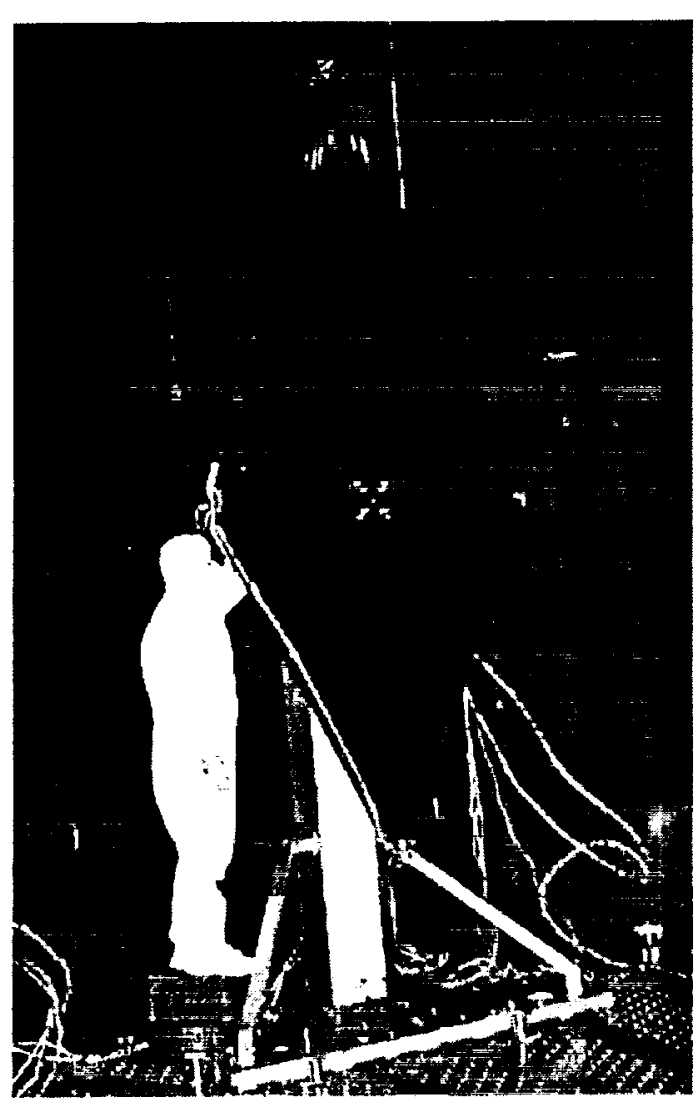

(c) Structure in Vacuum Chamber

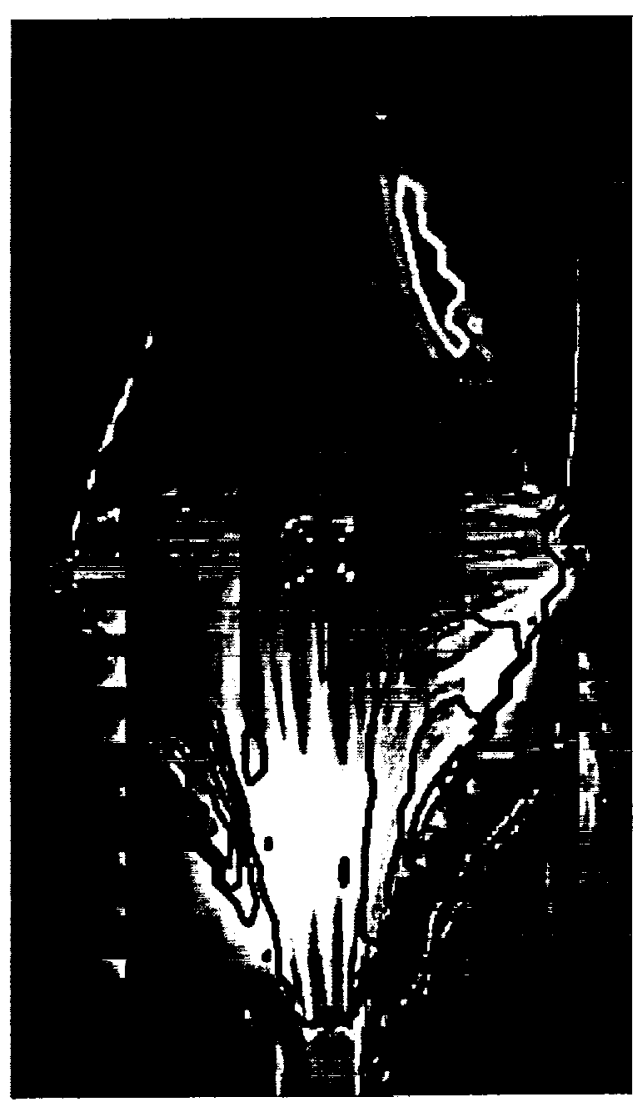

(d) Contour Lines of Identified Mode Shape at $1.8 \mathrm{~Hz}$

Figure 7 - One-Tenth-Scale NGST Sunshield Modal Test at GSFC. 


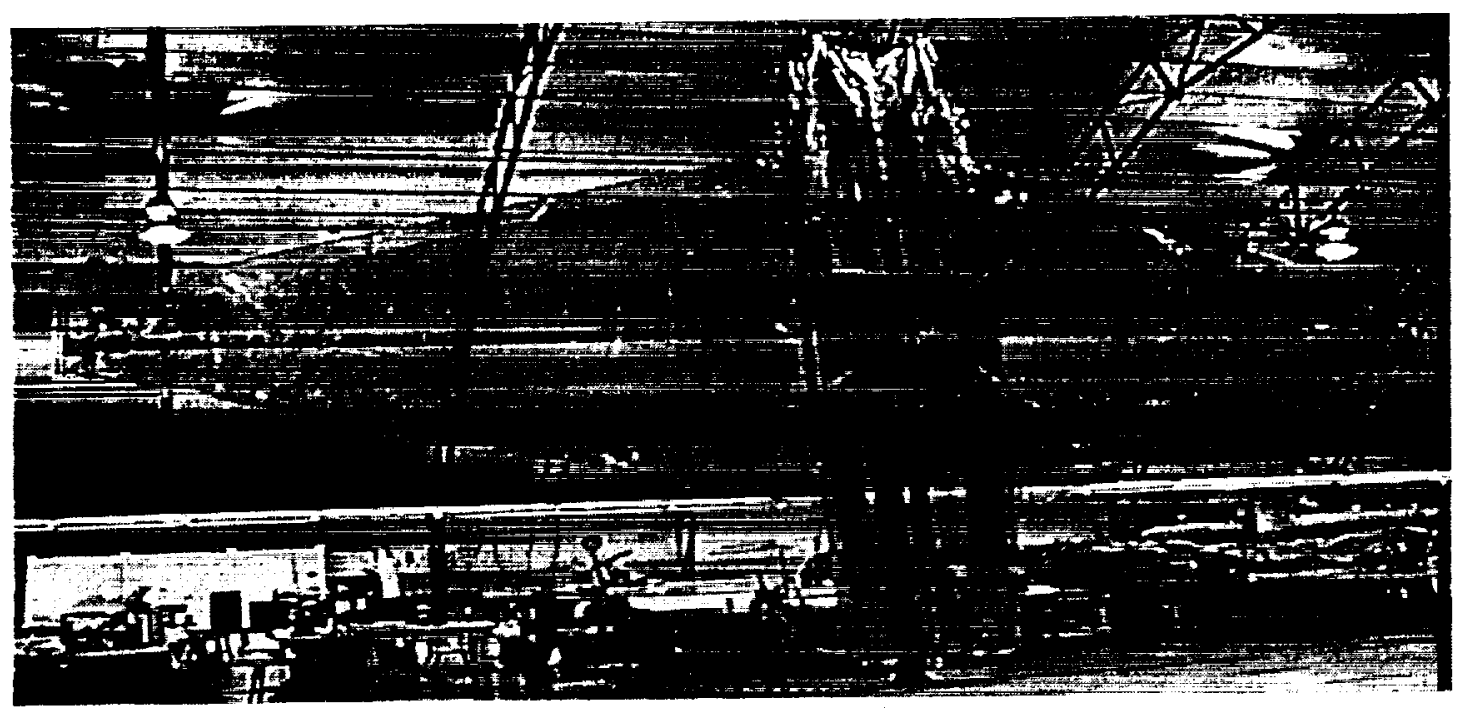

(a) Partially Deployed

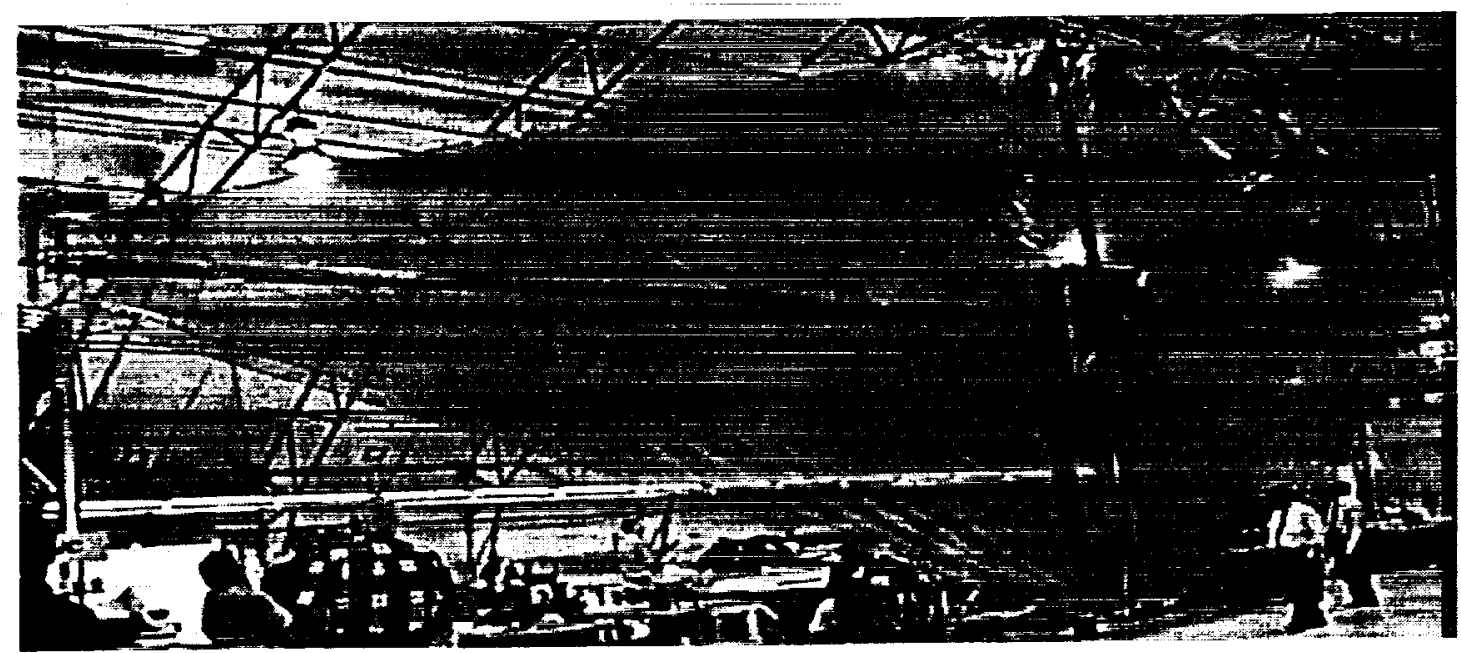

(b) Fully Deployed

Figure 8 - Deployment Demonstration of a One-Half-Scale NGST Sunshield Sponsored by GSFC.

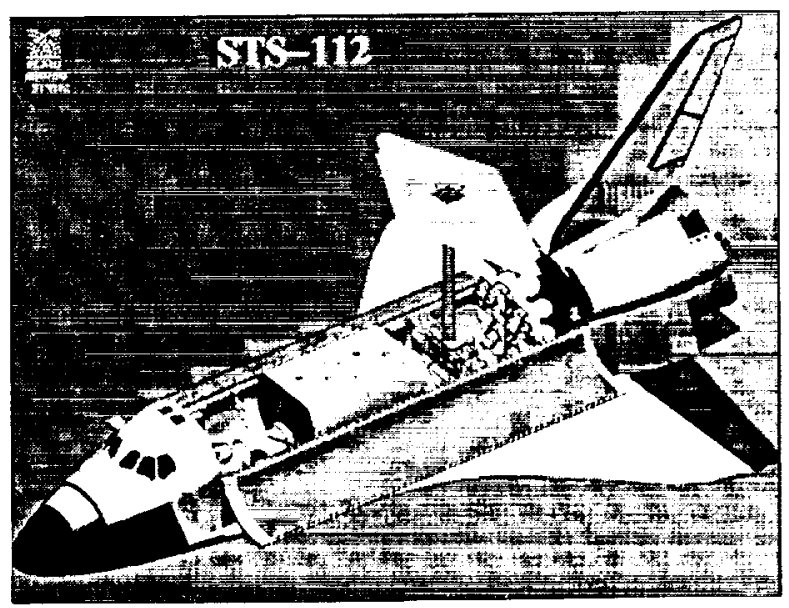

Figure 9 - Inflatable Sunshield in Space (ISIS) Experiment Developed by GSFC. 